\title{
A Study on the Predictive Maintenance Method of Fully Mechanized Mining Equipment based on Cost and Time Factors
}

\section{Xiangang Cao}

Xi'an University of Science and Technology

Tianbo Xu ( $\nabla$ xutianbo@xust.edu.cn)

Xi'an University of Science and Technology https://orcid.org/0000-0002-5393-9252

\section{Youjun Zhao}

xi'an coal mining machinery Co,.Itd

Jiangbin Zhao

Xi'an University of Science and Technology

Yan Wang

Xi'an University of Science and Technology

\section{Research}

Keywords: Fully mechanized mining equipment, Predictive maintenance, Maintenance cycle, Equipment failure rate, Equipment downtime rate

Posted Date: May 13th, 2021

DOI: https://doi.org/10.21203/rs.3.rs-515338/v1

License: (c) (i) This work is licensed under a Creative Commons Attribution 4.0 International License.

Read Full License 


\title{
A Study on the Predictive Maintenance Method of Fully Mechanized Mining Equipment based on Cost and Time Factors
}

\author{
Xiangang $\mathrm{Cao}^{1}$, Tianbo $\mathrm{Xu}^{1}$, Youjun Zhao ${ }^{2}$, Jiangbin Zhao ${ }^{1}$, Yan Wang ${ }^{1}$ \\ 1.School of Mechanical Engineering, Xi'an University of science and technology, Xi'an 710054, China \\ 2.Xi'an Coal Mining Machinery Co., Ltd, Xi'an 710032, China
}

\begin{abstract}
In view of the problems of excessive maintenance and insufficient utilization of equipment service life caused by preventive maintenance of fully mechanized mining equipment with fixed cycle, a predictive maintenance method is proposed. Firstly, based on Weibull distribution function and evolution rules of equipment decay, the evolution model of equipment failure rate is established; Then, the single-objective decision-making models of equipment maintenance cost rate and maintenance downtime rate are established respectively. On this basis, the multi-objective predictive maintenance planning model of fully mechanized mining equipment with comprehensive cost and time factors is established, and the optimal predictive maintenance cycle planning sequence is obtained. Combined with the coal production continuation plan, this paper puts forward a method to determine the optimal maintenance time by making suitable choices between advance maintenance and delay maintenance. The result confirms the effectiveness and superiority of the proposed method.
\end{abstract}

Keywords: Fully mechanized mining equipment, Predictive maintenance, Maintenance cycle, Equipment failure rate, Equipment downtime rate

\section{Introduction}

At present, mine construction in China is gradually moving towards the smart mine period, which has already been in the primary stage of intelligent development, with some large-scale coal mines realizing the intellectualization of main mining equipment (Wang et al. 2019, 2020). To ensure the continuous and reliable operation of equipment is the basis for the intelligent production of coal mines (Wang et al. 2019). Therefore, it is of paramount importance to formulate predictive maintenance strategies in line with the characteristics of coal mine production and improve the reliability of equipment.

Predictive Maintenance is an effective method to ensure high reliability and low cost operation of equipment. Its main purpose is to determine the most appropriate time for equipment maintenance (Huynh K.T. 2021). Benmansour R et al. discussed in detail the analysis and optimization of the mathematical model of equal period preventive maintenance strategy
(Benmansour R et al. 2014 ). In order to minimize the long-term average total cost, Liao Wenzhu et al. proposed a predictive maintenance model based on equipment pre- diagnosis information to obtain the optimal equipment maintenance threshold and maintenance cycle times (Liao et al. 2011). Liu Qingming et al. proposed a stochastic dynamic programming maintenance model on account of considering multiple fault states and spare parts inventory to obtain the optimal spare parts inventory and optimal maintenance strategy (Liu et al. 2013); C. Okoh et al. used reliability Weibull cumulative distribution function to model in order to predict the timing of rejection, replacement and reuse of the components (C. Okoh et al. 2017). Aiming at the lowest expected cost, Tsao Yu Chung et al. established the incomplete economic production (EPQ) model, with consideration of the predictive repair and rebuilt of defective products to determine the best predictive maintenance and production run time (Tsao et al. 2020). $\mathrm{Xu}$ Chang et al. used the intelligent safety predictive maintenance model based on convolution neural 
network to judge the running state of mining equipment, so as to provide the predictive maintenance scheme of equipment (Xu et al. 2021). Cheng Guoqing et al. jointly modeled and optimized the production lot size, quality control and predictive maintenance of a multi-stage production system composed of multiple equipment through series and parallel hybrid connection (Cheng et al. 2019). Zhu mixin et al. built the equipment decay model based on proportional failure rate to make preventive maintenance decision for multi-process flexible manufacturing system under variable load environment (Zhu et al. 2020); Shen Nanyan et al. introduced the time delay theory and established the optimal time optimization model of key equipment delayed maintenance to obtain the periodic maintenance plan of the production line (Shen et al. 2020). Cao Xiangang et al. established a multi-objective maintenance decision-making model integrating unsafe factors, maintenance cost and shutdown loss to obtain the maintenance scheme of fully mechanized mining equipment (Cao et al. 2020). O.F. Gurlu and M. Kumral proposed a method of fitting statistical distribution of life data with failure records to optimize the replacement time of drill bit in open-cast coal mines (O.F. Gurlu et al. 2019). Cheng et al. established a combined maintenance decision-making model constrained by risk function to minimize the maintenance cost under the condition of long-term operation of equipment, and obtained the optimal maintenance cycle and preventive maintenance threshold (Lu et al. 2019).

Although a large number of achievements have been made in the current research on predictive maintenance strategy of equipment, it is still insufficient for the maintenance of fully mechanized coal mining equipment. At present, the research object mainly focuses on ordinary workshop equipment (Dai et al. 2019) and some special equipment such as Wind turbines (Zhang et al. 2019) and EMU Components (Xiong and Wang 2021), however, the production characteristics and maintenance requirements of coal equipment are quite different from it, so it is difficult to apply these research results directly to the maintenance of coal mine equipment. Therefore, based on the characteristics of coal production and coal mine equipment maintenance, this paper formulates a suitable equipment maintenance strategy for coal production, including establishing a multi-objective predictive decision-making model that integrates the maintenance cost ratio model and maintenance downtime ratio model, planning the optimal predictive maintenance cycle sequence of the fully mechanized mining equipment, and proposing a method to determine the optimal maintenance time of the equipment which better suits coal mining due to its phased transfer characteristics.

\section{Problem Description and Basic Assumptions}

Coal mining is mainly conducted underground. The fully mechanized mining equipment includes shearer, hydraulic support, scraper conveyor, transfer machine and so on. Upon completion of a mining face, all equipment will be moved to a new mining face for continued use, which is called "moving upside down". In order to ensure the reliability of the equipment in the next mining face, coal mining enterprises generally choose to lift the equipment out of the mine and onto the ground to perform regular preventive maintenance. Although this equipment maintenance strategy ensures the reliability of equipment and the production continuity to a certain extent, it increases the cost caused by equipment lifting and transferring and also leads to the excessive maintenance of some equipment, which would definitely shorten their service time. In view of this dilemma, this paper proposes a predictive maintenance strategy for fully mechanized mining equipment, which reduces the excess maintenance of equipment and saves transfer time and expenses without detriment to the continuity of coal mining.

The predictive maintenance method of fully mechanized mining equipment proposed in this paper consists of two stages:

(1) Calculate the planning sequence of the optimal predictive maintenance cycle without considering the coal production continuity plan. Firstly, based on Weibull's distribution function and the evolutive rules of device decay, a model dictating the failure rate evolution of the equipment after multiple overhauls is 
established. Then, by considering maintenance time and expenses, establish maintenance cost ratio model and maintenance downtime ratio model respectively. On this basis, the multi-objective predictive maintenance planning model of fully mechanized mining equipment is established to obtain the theoretical optimal predictive maintenance cycle planning sequence.

(2) Taking into account the continued planning of coal production, adjust the sequence of predicted maintenance cycles of equipment. When a mining face is done, the remaining time of the current maintenance cycle, the length of the next working face in the continuation plan, the wasted life cost of advanced maintenance, the maintenance cost and opportunity loss caused by delayed maintenance are taken into consideration to determine whether to lift the equipment above ground for maintenance.

To simplify the model, this paper makes the following basic assumptions:

(1) There are two types of equipment maintenance methods according to the need for equipment to be lifted or not, namely, the underground minor repair and the aboveground overhaul. Minor repairs conducted underground include the maintenance of individual component of the equipment, as well as the physical disassembly and maintenance of major components. Aboveground overhaul refers to a comprehensive and thorough disassembly and examination of the equipment, guaranteeing the equipment has fully returned to its normal state with its nominal capacity.

(2) Underground minor repair can only make the equipment return to normal work, and does not change the failure rate of the equipment.

(3) The difference of maintenance effect caused by maintenance technology and method is not considered.

(4) The failure rates of early maintenance, on-time maintenance and delayed maintenance are the same.

(5) The impact of working conditions on equipment degradation is not considered.

\section{Multi-objective predictive maintenance cycle planning model for fully mechanized mining equipment}

\subsection{Equipment failure evolution model}

The key problem of maintenance decision-making is to determine the decline evolution law of equipment, and the accuracy of determination directly affects the maintenance effect of equipment. Practice has proved that Weibull distribution function can well describe the degradation of equipment, so this paper chooses two parameter Weibull distribution to establish the evolution model of equipment failure.

The failure rate function of device $i$ is expressed as follows:

$$
\lambda_{i}(t)=\frac{b_{i}\left(t^{b_{i}-1}\right)}{a_{i}^{b_{i}}}
$$

where $a$ is the scale parameter; $b$ is the shape parameter, $a>0, b>0$.

Considering the non-new effect of equipment repair and the aggravation of deterioration after maintenance, the service life decreasing factor and failure rate accelerating factor are introduced. The failure rate of equipment $i$ in the $j+1$ maintenance cycle can be expressed as follows (Xia et al. 2012 ):

$$
\lambda_{i(j+1)}(t)=\beta_{i j} \lambda_{i j}\left(t+\alpha_{i j} T_{i j}\right)
$$

where $\alpha_{i j}, \beta_{i j}$ represents the service life decreasing factor and failure rate accelerating factor of equipment $\mathrm{i}$ respectively, and $0<\alpha_{\mathrm{ij}}<1, \quad \beta_{i j}>1, t \in\left[0, T_{i(j+1)}\right]$.

\subsection{Single-objective maintenance cycle model}

\subsubsection{Equipment maintenance cost rate model}

In order to optimize the economy of equipment maintenance, the expenses related to maintenance activities are mainly considered, including the following two types of costs: the cost of underground minor repair and the cost of aboveground overhaul, which are expressed as $C_{i}^{m}$ and $C_{i}^{o}$, then the maintenance cost rate of equipment $i$ in the $j$ th maintenance cycle can be expressed as follows:

$$
c_{i j}=\frac{C_{i}^{o}+C_{i}^{m} \int_{0}^{T_{i j}} \lambda_{i j}(t) d t}{T_{i j}+T_{i}^{o}+T_{i}^{m} \int_{0}^{T_{i j}} \lambda_{i j}(t) d t}
$$

where $T_{i j}$ refers to the time interval of the $j$ th maintenance cycle of equipment $i ; T_{i}^{m}, T_{i}^{o}$ refers to the time required for single minor repair and overhaul 
respectively.

Using equation

(3) to get the derivation of $T_{i j}$, which is transformed into the following equation:

$$
\begin{aligned}
\lambda_{i j}\left(T_{i j}\right)\left(C_{i}^{m} T_{i j}\right. & \left.+C_{i}^{m} T_{i}^{o}-C_{i}^{o} T_{i}^{m}\right)-C_{i}^{m} \int_{0}^{T_{i j}} \lambda_{i j}(t) d t \\
& -C_{i}^{o}=0
\end{aligned}
$$

By solving equation (4), the optimal maintenance interval $T_{c i j}^{*}$ with the lowest maintenance cost rate, as well as the minimum maintenance cost rate $c_{i j}^{*}$, can be obtained.

\subsubsection{Equipment maintenance downtime model}

In order to improve the utilization rate of equipment, it is necessary to reduce the number of equipment maintenance, so as to reduce the proportion of maintenance downtime in the maintenance cycle. Equipment maintenance downtime rate can be expressed as follows:

$$
d_{i j}=\frac{T_{i}^{o}+T_{i}^{m} \int_{0}^{T_{i j}} \lambda_{i j}(t) d t}{T_{i j}+T_{i}^{o}+T_{i}^{m} \int_{0}^{T_{i j}} \lambda_{i j}(t) d t}
$$

Similarly, using equation (5) to get the derivation of $T_{i j}$, which is transformed into the following equation:

$$
-T_{i}^{o}-T_{i}^{m} \int_{0}^{T_{i j}} \lambda_{i j}(t) d t+T_{i}^{m} T_{i j} \lambda_{i j}\left(T_{i j}\right)=0
$$

By solving equation (6), the optimal maintenance time interval $T_{d i j}^{*}$ with the lowest equipment maintenance downtime rate, as well as the lowest equipment maintenance downtime rate $d_{i j}^{*}$, can be obtained.

\subsection{Multi-objective maintenance cycle model of equipment}

Because the dimensions of equipment maintenance cost rate and maintenance downtime rate are not consistent, it is necessary to normalize the dimensions of the two when they are combined to establish a multiobjective maintenance cycle model with, $c_{i j}^{*}$ and $d_{i j}^{*}$ being introduced, as shown in equation (7):

$$
D_{i j}=\omega_{i 1} \frac{c_{i j}}{c_{i j}^{*}}+\omega_{i 2} \frac{d_{i j}}{d_{i j}^{*}}
$$

where $\omega_{i 1}, \omega_{i 2}$ refers to the weight factor of equipment cost rate and utilization rate respectively, $\omega_{i 1} \geq 0, \omega_{i 2} \geq 0$, and $\omega_{i 1}+\omega_{i 2}=1$.
The goal of decision making is to get the optimal maintenance interval $T_{i j}^{*}$ with minimum $D_{i j}$. Analysis shows that the value of $D_{i j}$ should be between $T_{c i j}^{*}$ and $T_{d i j}^{*}$. Using $D_{i j}$ to get the derivation of $T_{i j}$, the following equation can be obtained:

$$
\begin{aligned}
& \frac{w_{i 1}}{c_{i j}^{*}}\left[\lambda_{i j}\left(T_{i j}\right)\left(C_{i}^{m} T_{i j}+C_{i}^{m} T_{i}^{o}-C_{i}^{o} T_{i}^{m}\right)\right. \\
& \left.-C_{i}^{m} \int_{0}^{T_{i j}} \lambda_{i j}(t) d t-C_{i}^{o}\right] \\
& -\frac{w_{i 2}}{d_{i j}^{*}}\left[T_{i}^{o}+T_{i}^{m} \int_{0}^{T_{i j}} \lambda_{i j}(t) d t\right. \\
& \left.-T_{i}^{m} T_{i j} \lambda_{i j}\left(T_{i j}\right)\right] \\
& =0
\end{aligned}
$$

By solving the above equation, the optimal maintenance interval $T_{i j}^{*}$, which combines the maintenance cost rate and maintenance downtime rate, can be obtained.

\section{Solution of decision-making model}

On the basis of the equipment failure evolution model, according to the established single-objective maintenance cycle model and multi-objective maintenance cycle model, the optimal predictive maintenance cycle sequence within the life cycle of the equipment can be planned in a circular and progressive manner. The decision-making algorithm is shown in Figure 1. The specific algorithm steps are as follows:

(1) Determine the initial parameter values for the maintenance decision-making, including $C_{i}^{m}, C_{i}^{o}, T_{i}^{m}$, $T_{i}^{o}$. The scale parameter a and shape parameter $\mathrm{b}$ of Weibull distribution function are determined according to the historical failure data of the equipment, and the initial failure rate function $\lambda_{i 1}(t)$ is obtained.

(2) The single-objective decision-making of maintenance cost rate and that of maintenance downtime rate are made to obtain the lowest maintenance cost rate $c_{i 1}^{*}$ and maintenance downtime rate $d_{i 1}^{*}$, and the corresponding optimal maintenance interval $T_{c i 1}^{*}$ and $T_{d i 1}^{*}$.

(3) Determine the weight factor of multi-objective maintenance decision-making $\omega_{i 1}$ and $\omega_{i 2}$. Then the optimal maintenance period $T_{i 1}^{*}$ in the case of multi- 
objective is calculated by bringing in the result of single-objective maintenance decision-making.

(4) To determine whether $\sum_{j} T_{i j}^{*}$ is greater than the designed service life $T_{D}$ of the equipment. If so, the maintenance decision-making is over; if not, carry out the next round of predictive maintenance cycle calculation.

(5) According to the historical failure and maintenance data of the same kind of equipment, determine the values of the decline factor of service life $\alpha_{i 1}$ and failure rate acceleration factor $\beta_{i 1}$ and bring them into equation (2) to determine the device failure rate function $\lambda_{i 2}(t)$ after the first above-ground maintenance. Assign $j=j+1$ and proceed to step (2) for the next-round calculation of predicted maintenance cycle.

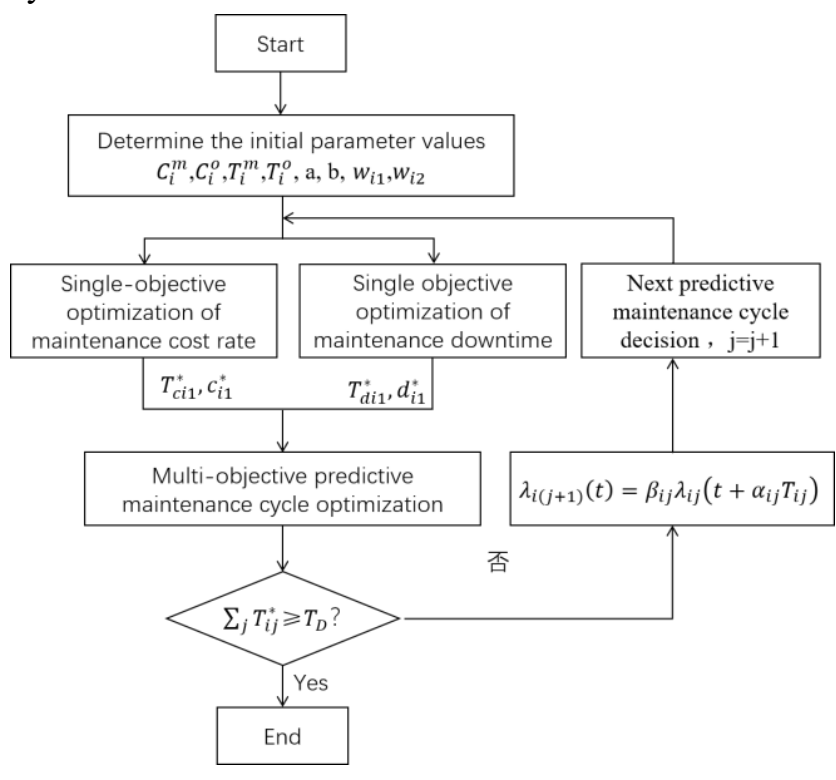

Fig.1 Multi-objective predictive maintenance process

\section{Adjustments to the anticipated maintenance cycle}

After the model is solved, the optimal maintenance cycle sequence can be obtained. Due to the influence of failure rate acceleration factor, the interval time of the cycle sequence shows a trend of gradual reduction, which can be used to guide the predictive maintenance of the equipment. There are three possible scenarios when actual predicted maintenance is carried out in conjunction with a coal mining continuation plan:

(1) When the mining task of a face is completed, the current predicted maintenance cycle is not over, and the time from the end of the current maintenance cycle is greater than the mining cycle for the next face in the continuation plan, as shown in Figure 2, mining task M1, the fully mechanized coal mining equipment does not need to be overhauled, and can be directly transported to the new working face for installation and use.

(2) When the mining task of a face is finished and the current predictive maintenance cycle just is just over, the equipment will be overhauled above-ground and the spare equipment will be put into use at the same time. The equipment will be used as spare equipment after maintenance is completed.

(3) When the mining task of a face is completed, the current predictive maintenance cycle is not over, and the time from the end of the current maintenance cycle is less than the mining cycle for the next mining face in the continuation plan, such as the mining task M2 in Figure 3, the equipment overhaul at the end of the current predictive maintenance cycle will cause the mining process of the next face (M3) to be interrupted, which should be avoided as far as possible in the coal production. In such cases, either upgrade the equipment in advance or postpone it until next mining face is completed. The choice should be made by calculating the increase in costs associated with both options through equation (9) and equation (10). If $c_{a}>c_{d}$, indicating that early maintenance is more expensive than delayed repair, the equipment maintenance should be delayed until the next mining face is finished, as shown in Figure 2; Similarly, if $c_{a}<c_{d}$, the equipment should be maintained in advance and the spare equipment should be put into operation, as shown in Figure 3. In addition, whether the maintenance is advanced or delayed, the remaining predictive maintenance cycle should be advanced or delayed accordingly.

$$
c_{a}=\frac{T_{i j}^{*}-\sum T_{M}}{T_{D}} \times P
$$

where $c_{a}$ represents a waste of equipment life costs due to early repairs; $\sum T_{M}$ is the time spent on all mining tasks completed in maintenance cycle $\mathrm{j} ; \mathrm{P}$ is the cost for equipment purchase. 


$$
c_{d}=\left(C_{i}^{m}+C_{i}^{d}\right) \times \int_{T_{i j}^{*}-\sum T_{M}}^{T_{M+1}} \lambda_{i j}(t) d t
$$

Where $c_{d}$ represents the maintenance cost due to

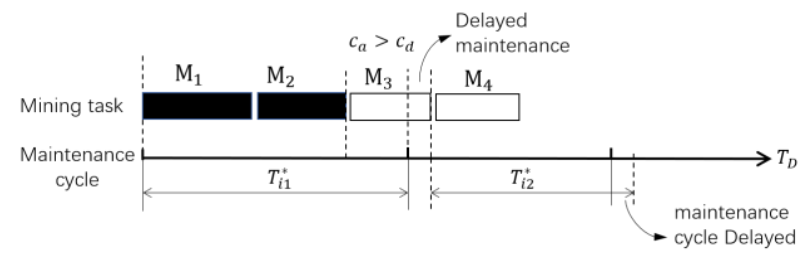

Fig.2 Delayed maintenance of equipment

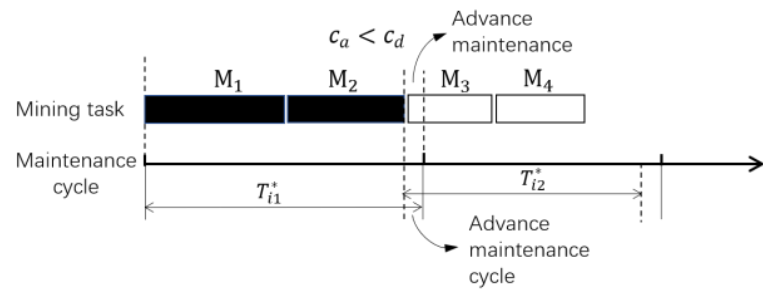

Fig.3 Equipment maintenance in advance

\section{Example and result analysis}

delayed maintenance; $C_{i}^{d}$ refers to the shutdown loss caused by equipment failure; $T_{M+1}$ refers to the time required to complete the next mining task.

\subsection{The initial parameters of the equipment}

Taking a certain type of shearer as an example, this paper assumes that the distribution of failure rate follows Weibull function, and uses its historical failure data to fit the initial scale parameters and shape parameters; The designed service time of the shearer is calculated by dividing the designed coal production in the whole life cycle of the equipment by the amount of coal dropping per hour; Considering that with the increase in the number of shearer maintenances, the effect of each repair gradually decreases and the frequency of failures increases, the values of the service life decreasing factor and failure rate accelerating factor are designed to gradually increase with the increase of maintenance times. The initial parameters of maintenance decision-making are shown in Table1.

Table 1 maintains the initial parameters of the decision

\begin{tabular}{lc|lc}
\multicolumn{1}{c|}{ Entry } & Numerical & \multicolumn{1}{c}{ Entry } & Numerical \\
\hline Design life $T_{D}(\mathrm{~h})$ & 50000 & scale parameter a & 9000 \\
Overhaul time $T_{i}^{o}$ (h) & 960 & shape parameter b & 5 \\
Overhaul cost $C_{i}^{o}$ (Yuan) & 1000000 & service life decreasing factor $\alpha_{i j}$ & $\mathrm{j} /(\mathrm{j}+19)$ \\
Minor repair time $T_{i}^{m}$ (h) & 16 & failure rate accelerating factor $\beta_{i j}$ & $\left(\mathrm{j}^{2}+16\right) /(2 \mathrm{j}+14)$ \\
Minor repair $C_{i}^{m} \operatorname{cost}$ (Yuan) & 50000 & weight factor $\omega_{i 1}, \omega_{i 2}$ & $0.5,0.5$ \\
\hline
\end{tabular}

\subsection{Analysis of the Predictive maintenance result}

Perform the flow shown in Figure 2 to solve the multiobjective predictive maintenance cycle planning model, and output the decision results of single-objective and multi-objective maintenance cycle respectively, as shown in Table 2.

Table 2 Results of the predicted maintenance cycle planning

\begin{tabular}{cccccccc}
\hline \multicolumn{3}{c}{$\begin{array}{c}\text { Maintenance cost rate } \\
\text { model }\end{array}$} & \multicolumn{3}{c}{ Maintenance downtime model } & \multicolumn{3}{c}{ Multi-objective predicted maintenance } \\
model
\end{tabular}




$\begin{array}{rrrrrrrrr}11602 & 98.9 & 0.0823 & 14780 & 112.1 & 0.0759 & \mathbf{1 2 8 3 9} & 100.9 & 0.0782 \\ 11085 & 104.3 & 0.0862 & 14242 & 118.5 & 0.0793 & \mathbf{1 2 3 2 1} & 106.5 & 0.0818 \\ 10467 & 111.1 & 0.0911 & 13559 & 126.4 & 0.0837 & \mathbf{1 1 3 3 7} & 113.5 & 0.0864\end{array}$

(1) From the operation results, it can be seen that the whole life cycle of the shearer is divided into four overhaul maintenance cycles, and the interval time between maintenance cycles shows a decreasing trend, as shown in Figure 4. The decrease in optimal maintenance intervals $T_{i j}^{*}$ means that the frequency of predictive maintenance is gradually increasing due to an increase in equipment failure rates.

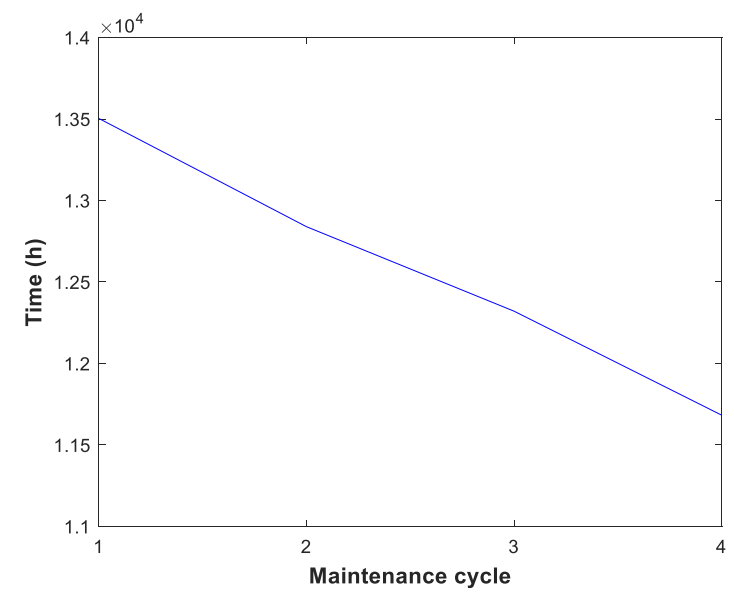

Fig.4 The trend of predicted maintenance cycle length

(2) The increase in maintenance cost rate and maintenance downtime rate corresponding with Maintenance cycle $T_{i j}^{*}$ reflects that with the increase in equipment service time and the number of overhauls, the frequency of equipment failure will also increase, resulting in the increase in the number and cost of equipment maintenance as well as in the time spent on maintenance activities, as shown in Figure 5.
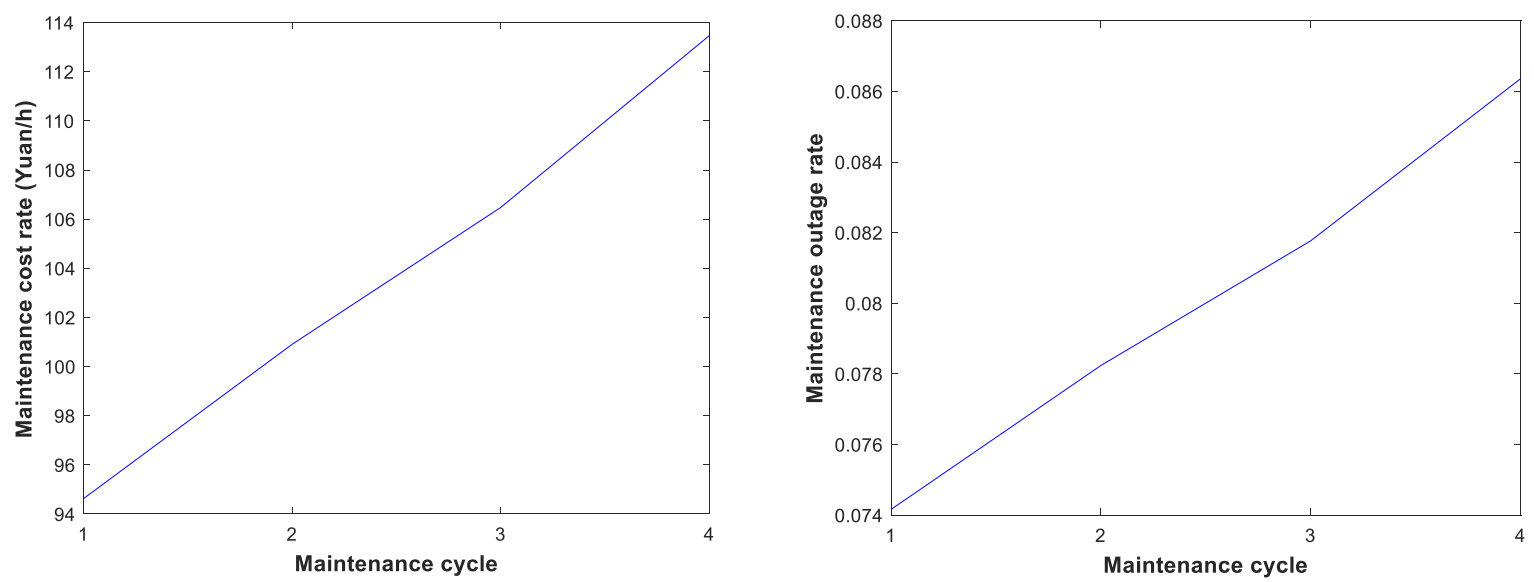

Fig.5 Trend of maintenance cost rate and maintenance downtime rate

(3) It is assumed that the time required for mining tasks is $3000 \mathrm{~h}$. If the production is arranged according to the method of fixed maintenance cycle of $10000 \mathrm{~h}$, the mining and maintenance situation of the shearer during the life cycle is shown in Figure 6. In theory, the life cycle of the shearer should have 5 maintenance cycles, but due to the early maintenance of each maintenance cycle, the maintenance is over maintained and the actual 
life of the equipment is shortened. The shearer has gone through 4 maintenance cycles, with a total of 12 surfaces being mined, 3 above-ground overhauls in advance and the life utilization rate of the equipment being $72 \%$. If the mining task is arranged according to the above-mentioned predicted maintenance planning cycle, the maintenance situation of the shearer in the whole life cycle is shown in Figure 7, with a total of 17 faces being mined, 4 maintenance cycles, and 3 aboveground overhauls, among which the first being delayed than the planning, and the last two in advance. The total production time is slightly longer than the design life, and the utilization rate of equipment life is $102 \%$. The results of two maintenance methods are shown in Table 3.

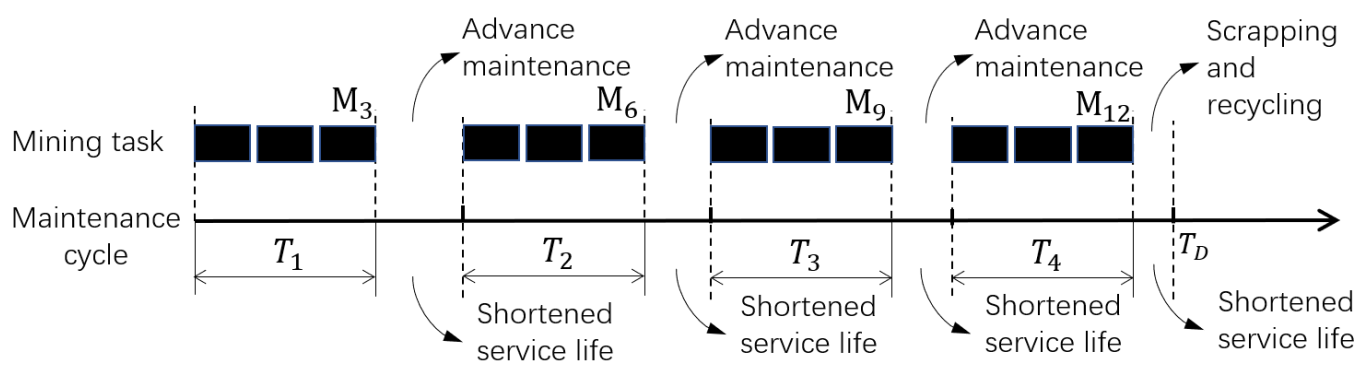

Fig.6 Equipment maintenance with fixed maintenance cycle

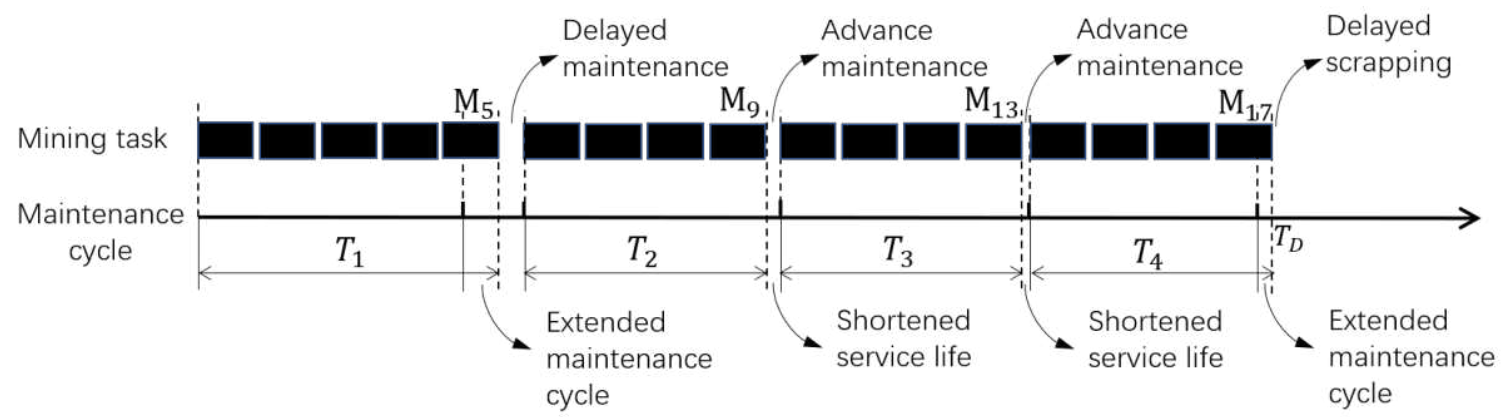

Fig.7 Equipment maintenance with decreasing maintenance cycle

Table 3 Comparison of two maintenance methods

\begin{tabular}{cccccccc}
\hline $\begin{array}{c}\text { Maintenance } \\
\text { mode }\end{array}$ & Cycles & Mining face & $\begin{array}{c}\text { Overhaul } \\
\text { times }\end{array}$ & $\begin{array}{c}\text { overhauls } \\
\text { and } \\
\text { scrapping in } \\
\text { advance }\end{array}$ & $\begin{array}{c}\text { Delayed } \\
\text { overhaul } \\
\text { and } \\
\text { scrapping }\end{array}$ & $\begin{array}{c}\text { Mining } \\
\text { time }\end{array}$ & $\begin{array}{c}\text { Service life } \\
\text { utilization }\end{array}$ \\
\hline $\begin{array}{c}\text { Fixed } \\
\text { maintenance } \\
\text { cycle }\end{array}$ & 4 & 12 & 3 & 4 & 0 & 36000 & $72 \%$ \\
$\begin{array}{c}\text { Predictive } \\
\text { maintenance } \\
\text { cycle }\end{array}$ & 4 & 17 & 3 & 2 & 2 & 51000 & $102 \%$ \\
\hline
\end{tabular}

With the latter equipment maintenance method, there are two early repairs, so the equipment life utilization rate is still possible to improve. Therefore, in the production practice, in order to improve the utilization rate of equipment life cycle, managers should comprehensively consider the optimal maintenance cycle and mining tasks, make overall arrangements for appropriate equipment to complete the work, shorten the time spent on early maintenance and scrapping as much as possible. 


\section{Conclusion}

(1) Based on the single-objective maintenance cycle decision-making model of maintenance cost rate and maintenance downtime rate, a multi-objective predictive maintenance cycle planning model for fully mechanized mining equipment is established. By solving the model, the overhaul cycle of fully mechanized mining equipment is planned, which improves the traditional way of equipment maintenance which rely only on fixed maintenance cycle.

(2) The method of determining the maintenance time of fully mechanized mining equipment is proposed. Combined with the coal production continuation plan, the optimal predictive maintenance planning cycle solved by the multi-objective model is adjusted. Whether or not having the above-ground overhaul is decided by comparing the additional expenses caused by the advance maintenance and the delay maintenance.

(3) Combined with the example, the results of predictive maintenance planning are analyzed, and the multi-objective predictive maintenance cycle planning model and equipment maintenance time determination method are proved to be more effective and superior than the fixed cycle equipment maintenance method.

\section{Acknowledgements}

This work was supported by the National Natural Science Foundation of China (NSFC) under grant 51834006 and 51875451.

\section{Compliance with Ethical Standards}

Conflicts of Interest: The authors declared that there is no conflict of interest in this paper.

\section{References}

Wang GF, Liu F, Pang YH et al. (2019) Coal mine intellectualization: the core technology of high quality development. Journal of China Coal Society 44(2): 349-357.

Wang GF, Pang YH, Ren HW (2020) Intelligent coal mining pattern and technological path. Journal of Mining and Strata Control Engineering 2(1): 5-9.

Wang GF, Liu F, Meng XJ, et al. (2019) Research and practice on intelligent coal mine construction. Coal Science and
Technology 48(8): 1-36.

Huynh K.T. (2021) An adaptive predictive maintenance model for repairable deteriorating systems using inverse Gaussian degradation process. Reliability Engineering \& System Safety, prepublish: 107695.

Benmansour R, Allaoui H, Artiba A, et al. (2014) Minimizing the Weight sum of Maximum Earliness and Maximum Tardiness Costs on a Single Machine with Periodic Preventive Maintenance. Computers \& Operations Research, 47: 106-113.

Liao WZ, Yu BH, Pan ES, et al. (2011) Single-machine-based Predictive Maintenance Model Based on Machinery Prognostics Information. Industrial Engineering and management 16(5): 117-122.

Liu QM, Dong M, Peng Y (2013) A dynamic predictive maintenance model considering spare parts inventory based on hidden semi-Markov model. Proceedings of the Institution of Mechanical Engineers, Part C: Journal of Mechanical Engineering Science 227(9): 2090-2103.

C. Okoh, R. Roy, J. Mehnen (2017) Predictive Maintenance Modelling for Through-Life Engineering Services. Procedia CIRP 59:196-201.

Tsao YC, Lee PL, Liao LW, et al. (2020) Imperfect economic production quantity models under predictive maintenance and reworking. International Journal of Systems Science: Operations \& Logistics 7(4): 347-360.

Xu C, Wang DY, Li JZ, et al. (2021) Intelligent Safety Monitoring and Predictive Maintenance System for Mining Equipment. Industrial and Mining Automation 47(3): 79-88.

Cheng GQ, Zhou BH, Li L (2019) Joint Optimization of Production Quantity, Quality Control and Predictive Maintenance for Production Systems with Multiple Machines. Systems Engineering-Theory \& Practice 39(8): 2152-2161.

Zhu MX, Ge YX, Zhou XJ (2020) Preventive Maintenance Strategy for Multi-Stage Flexible Manufacturing System with Dynamic Production Planning. Journal of Shanghai Jiao Tong University 54(11): 1124-1133.

Shen NY, Wu X, Li J, et al. (2020) Research on Pre-maintenance Strategy of Key Equipment in Automatic Production Line. Journal of Mechanical Engineering 56(21): 231-240.

Cao XG, Gong YR, Luo X, et al. (2020) Research on maintenance decision optimization of coal mine fully mechanized mining equipment based on genetic algorithm. Coal Engineering 
52(6): 164-169.

O.F. Gurlu, M. Kumral (2019) Optimization of drill bit replacement time in open-cast coal mines. International Journal of Coal Science \& Technology 6(3): 399-407.

Lu C, Xu TX and Cong LH (2019) Condition-based maintenance decision based on inverse gaussian deterioration process under the condition of regular detection and maintenance. Journal of Intelligent \& Fuzzy Systems 37: 5767-5775.

Dai BC, Zhang YJ, Li YF, et al. (2019) Preventive Maintenance Method of CNC Machine Tools Based on Performance Degradation Prediction. China Mechanical Engineering 30(17): 2122-2128.
Zhang XH, Zeng JC, Shi GN, et al. (2019) Optimal decision of condition-based maintenance of wind turbines based on deterioration state-space partition. Control and Decision34(9): 1909-1916.

Xiong L, Wang H (2021) Multi-level Imperfect Maintenance Strategy for EMU Components from the Perspective of Failure Risks. China Mechanical Engineering 32(4): 399406.

Xia TB, Xi LF, Zhou XJ, Jay Lee (2012) Dynamic maintenance decision-making for series-parallel manufacturing system based on MAM-MTW methodology. European Journal of Operational Research221(1): 231-240. 